\title{
Are Patients with Covid 19 have More Risk for those with COPD?
}

\author{
AA Mamun $\mathrm{SM}^{1 *}$, Islam $\mathrm{QT}^{2}$, Sarker $\mathrm{SU}^{3}$ and Mannan $\mathrm{S}^{4}$ \\ ${ }^{1}$ Senior Consultant \& coordinator of Respiratory Medicine, Square Hospitals, Bangladesh \\ ${ }^{2}$ Professor of Medicine, Popular Medical College, Bangladesh \\ ${ }^{3}$ Specialist, Respiratory Medicine, Square Hospitals, Bangladesh \\ ${ }^{4}$ Registrar of Respiratory Medicine, University hospital Coventry \&Warwickshire, UK
}

\section{Review Article \\ Volume 6 Issue 1}

Received Date: April 14, 2021

Published Date: April 28, 2021

DOI: $10.23880 /$ oajprs-16000137

*Corresponding author: SM AA Mamun, Senior Consultant \& coordinator of Respiratory

Medicine, Square Hospitals, Dhaka, Bangladesh, Tel: 88-01841504999; Email: mamundr69@gmail.com

\section{Abstract}

The SARS-CoV-2 virus causes the illness COVID-19, which may lead to mild to severe respiratory problems. These symptoms are more severe in people with chronic obstructive pulmonary disease (COPD) have a higher risk of more severe illness from COVID-19 due to their existing lung problems. Based on our existing knowledge, Experience of last one year \& meta analysis of different study report, this review has taken the initiative to find the answer of few key question: Firstly is the COPD patient have increased risk of Covid19. Secondly, do systemic corticosteroids offer protection against COVID-19 with COPD or not? And, finally, what is the evidence regarding use of MDI or Nebulization \& NIV as standard treatment. This up-to-date review will make scope for some of the key issues which have significant impact on the long-term outlook for COPD patients in the context of COVID-19.

Keywords: COVID-19; COPD; NIV

\section{Introduction}

As the coronavirus outbreak quickly surges worldwide \& the healthcare systems around the world are currently under great pressure due to the COVID-19 outbreak, identification of those who are at high risk is crucial. COVID-19 infection is often more severe in people of $60+y$ rs or with co morbidities like COPD, Heart failure, uncontrolled diabetes or conditions that affect their immune system. As the virus SARS-CoV-2 primarily affecting the upper \& the lower respiratory tract (windpipe and lungs), patients with pre- existing disease of respiratory tract have a higher risk of more severe illness from COVID-19 [1].

Most common causes of exacerbation of COPD is infection. This may be bacterial, viral or any other infection. Corona virus is one of the virus responsible for acute exacerbations of COPD (AECOPD). In this pandemic situation it is of great need to identify whether this exacerbation is due to Covid19 or any other causes are responsible for it. Most common symptoms of exacerbation are increased SOB, changes in colour of sputum. Thus, a patient presented with these symptoms with sore throat, headache, loss of smell, fever, malaise, bodyache, diarrhea, conjunctivitis or any other new symptoms in association with above two symptoms may warrant the cause of exacerbation is Covid-19.

People with severe COPD may have a higher risk of COVID-19 complications as COVID-19 affects the respiratory system. Their existing lung condition having more difficult to fight an infection which is already compromised. According to a meta-analysis of seven studies, the researchers concluded that those with COPD may have more risk of developing severe COVID-19 infections [2]. 


\section{Open Access Journal of Pulmonary \& Respiratory Sciences}

After infection with COVID-19 in COPD patients, they should not be panic, they should take their regular medication, follow the guidelines to help protect themselves and others against the virus. Patients with mild symptoms should treated at home by following their usual COPD treatment plan and carefully monitoring their symptoms [3].

In case of more severe cases, people will need treatment in a hospital to treat or prevent complications. Occasionally, people may require supplemental oxygen and advanced support for the respiratory system and other organs.

Taking protein rich diet and drinking plenty of water can also help to support the body to boost up the immune system and remove excess mucus from the lungs. Eating less carbohydrates and more healthy fats improve breathing in COPD patients. The American Lung Association have a selection of breathing exercises that may help ease shortness of breath and relax the airways [4].

\section{The Airway of COPD \& Chronic Smoker are More Vulnerable for COVID-19 Infection}

After contacting with SARS COV-2, why COPD patients appear to suffer worse outcomes is worth some speculation. First, recent evidence suggest that patients of COPD and those of chronic smokers may display the machinery required for SARS-CoV-2 cellular entry has come to light. Similar to SARS-CoV (which was responsible for the 2002-2003 SARS pandemic) [5], SARS-CoV-2 bears an envelope spike protein that is primed by the cellular serine proteaseTMPRSS2 to facilitate fusion of the virus with the cell's angiotensinconverting enzyme 2 (ACE-2) receptor and subsequent cell entry (Figure 1) [6-9].

ACE-2 expression was significantly elevated in the airway of COPD patients compared to control subjects [10], demonstrated by Research group that in three separate cohorts with available gene expression profiles from bronchial epithelial cells. In an observational study data suggest that, current smoking was also associated with higher ACE-2 expression compared with former and non smokers \& subsequently this report have been validated by other groups in separate cohorts of lung tissue and airway epithelial samples [11-14] and supported by additional evidence linking ACE-2 expression with nicotine exposure [12,15,]. It is important to note, though, that ACE-2 expression alone has not been shown yet to confer increased susceptibility or increased severity of disease.

Moreover, the relatively low expression of ACE- 2 in the bronchial epithelium in comparison to the nasal epithelium [16] has unclear implications for disease susceptibility in patients with predominantly small airways pathology.

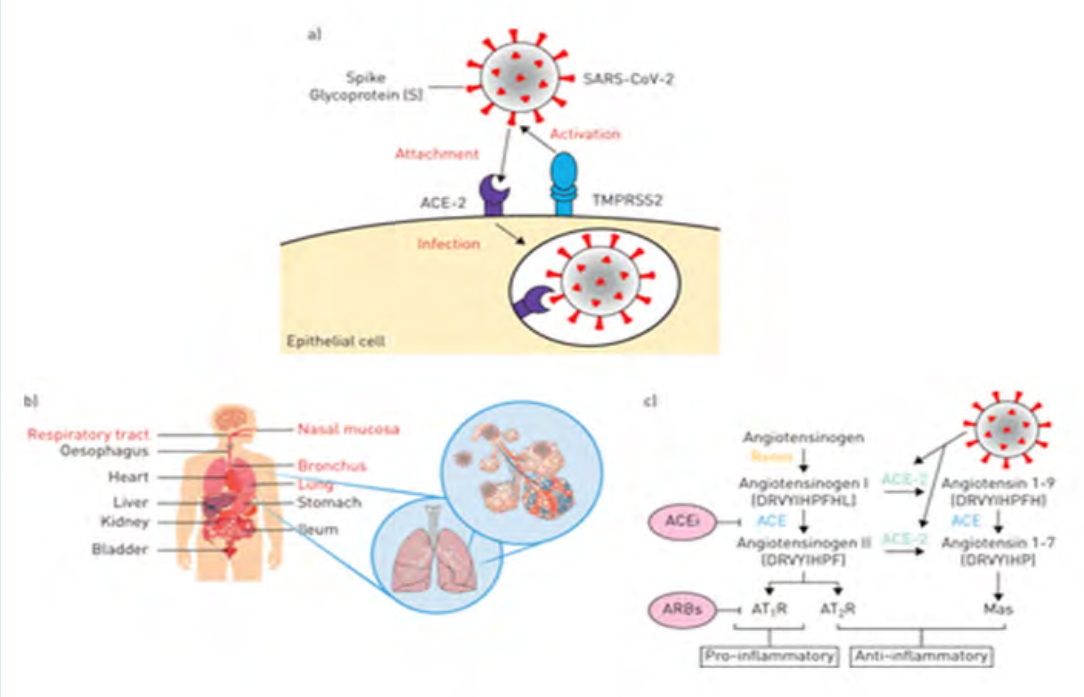

Figure 1: Schematic representation of a) severe acute respiratory syndrome coronavirus 2 (SARS-CoV-2) binding to the angiotensin-converting enzyme 2 (ACE-2) receptor following activation of the spike protein (s) by transmembrane serine protease 2 (TMPRSS2), which leads to endocytosis and infection. b) Human organs that have shown ACE2 expression, with the respiratory system highlighted in red. c) The renin-angiotensin system (RAS) and the proposed SARS-CoV-2 action. The generation of angiotensin II from angiotensin I by angiotensin-converting enzyme (ACE) induces vasoconstriction of blood vessels and pro-inflammatory effects through the binding of angiotensin II receptor type 1 (AT1R) Courtesy: European Respiratory Journal. 


\section{Open Access Journal of Pulmonary \& Respiratory Sciences}

\section{Is There any Extra Precautions to be Taken}

People with COPD should continue their treatment for COPD as usual during the COVID-19 outbreak. They should keep at least a 30-day supply of any prescription medication and preferably a 90-day supply. People can check with their oxygen provider to ensure that their routine oxygen supply. Should complete their influenza and pneumococcal vaccine.

Antibiotics: Co-infections with Bacteria or fungus are uncommon in mild to moderate COVID-19: Meta-analysis has shown that only $8 \%$ of patients had a bacterial/fungal co-infection [17]. The risk of co-infections increases with the severity of COVID-19: a cohort study on risk factors for in-hospital death from COVID-19 found that 50\% of non-survivors experienced secondary infections and that ventilator associated pneumonia was seen in 31\% [18]. Since as it may be difficult to distinguish SARS-CoV-2 infections from a bacterial pneumonia and because patients with COPD are at risk for bacterial (super) infections, we suggest treating hospitalized patients with COPD and COVID-19 with broad-spectrum antibiotics, guided by local/national guidelines for treating pneumonia. This is in line with the current WHO treatment guideline for severe COVID-19(19). Microbiological analysis, such as sputum culture, should be performed on admission and it may then be reasonable to stop antibiotics in the absence of a coinfection.

Bronchodilators and Nebulisation: Bronchodilators are frequently given via nebuliser in hospitalized patients with COPD. The British Thoracic Society (BTS) guideline on treating patients with COPD and COVID-19 supports the use of nebulisers, claiming there is no evidence supporting an increased risk of viral transmission and, second, that aerosols surrounding the nebuliser come from the nebuliser not from patients [19].

Alternative modes of inhalation are available, including pressurised metered-dose inhalers (pMDI) used with a spacer. In AECOPD pMDIs are not inferior to nebulisers [20].

Claiming as one of the aerosol generating procedure, since the safety of nebulisers is controversial and given that there is a suitable alternative, we recommend bronchodilators administered by pMDI and spacer over the use of nebuliser treatment in mild to moderate symptomatic patients with COPD and COVID-19.

Nebulization should be reserved for those situations in which pMDI with spacer is not possible, such as patients with severe, life-threatening disease or those unable to use a pMDI. For healthcare workers, respiratory masks (FFP-3 or equivalent) and other personnel protective equipment should be used during aerosol-generating procedures such as nebulisers [21].

Systemic Corticosteroids: The efficacy of corticosteroids in general for treating COVID-19 shows beneficial effect, in different cohort study suggested steroids might improve clinical outcome in patients with COVID-19 .Recent, preliminary results from the Randomized Evaluation of COVID-19 Therapy (RECOVERY) trial have shown that dexamethasone improves mortality in patients with COVID-19 requiring respiratory support [22]. Although, WHO recommended against the use of steroids earlier, but is now updating treatment guidelines to include dexamethasone or other corticosteroids.

Corticosteroids are beneficial to patients with severe AECOPD, especially in patients requiring ventilatory support in whom steroids reduce ventilation days and NIV failure; therefore, it is reasonable to treat patients with COPD and severe COVID-19 with course of corticosteroids. The RECOVERY regimen of $6 \mathrm{mg}$ dexamethasone once daily could be used until more evidence is provided to guide treatment in patients with COPD with COVID-19 [23].

Controlled Oxygen Therapy \& HFNC: Patients with hypoxaemic COPD and COVID-19 should be given controlled oxygen therapy as the first step [24]. If hypoxaemia is insufficiently controlled with maximum oxygen supplementation by face mask, high-flow nasal cannula (HFNC) or CPAP with high oxygen flow should be considered.

HFNC has recently been suggested as a management option in patients with COVID-19 with acute hypoxaemic respiratory failure [23]. Reduction of hypercapnia and work of breathing might be additional benefits of HFNC in patients with COPD and COVID-19 [25].

As HFNC is an open system and expiration cannot be filtered, a surgical mask can be placed over the nasal cannula to limit aerosol spread [25]. Besides HFNC, CPAP with a high fraction of inspired oxygen $\left(\mathrm{FiO}_{2}\right)$ might be an option to treat hypoxaemic respiratory failure. CPAP provides a certain level of positive end-expiratory pressure, which might be a useful add-on to oxygen supplementation.

Furthermore, it is possible to filter expiration with CPAP and thus limit viral spread. In patients with COPD with acute (on chronic) hypercapnic respiratory failure, NIV should be considered [26].

IMV should be instituted in patients with severe type 2 respiratory failure or after NIV failure [24]. Particularly in COPD, this decision should be made carefully, as it is known that in-hospital mortality with IMV in AECOPD 


\section{Open Access Journal of Pulmonary \& Respiratory Sciences}

is high [26]. Mortality is even higher for patients with COPD with severe COVID-19 and the prolonged duration of mechanical ventilation seen in patients with COVID-19 might be particularly detrimental to the future health status of patients with COPD.

\section{Special Precaution for COPD Patients:}

1. Try to stay at home always.

2. If necessary to go out, stay 6 feet away from others with mask.

3. Hands should regularly wash, and particularly after being in a public place, with soap and warm water for 20 seconds.

4. Ensure to have enough food stored in the house with fruits if possible.

5. Where possible, get items delivered or ask others to drop items off to avoid excess travel.

6. If people live with others or health care team entering the home, make sure they frequently wash their hands for 20 seconds with warm water and soap or use sanitisers.

7. Clean and disinfect surfaces that people touch frequently, such as door handles, countertops, remote and bathroom surfaces.

8. Don't touch the face with unwashed hands.

9. Quit smoking if continuing, that can help to strengthen the respiratory system against COVID-19.

\section{Conclusion}

People with COPD are always vulnerable to lower respiratory tract infection. This is because of existing damage to the lungs \& airways. This group of patients are at higher risk during Covid19 pandemic due to overexpression of ACE2 receptor in Airways.

People with COPD should take extra precautions to protect themselves from contracting the SARS-CoV-2 virus and developing COVID-19. It is important to stay home unless it is essential to go out. Hand washing and keeping a clean home also help to prevent the spread of viruses If people do develop symptoms of COVID-19, they can call their doctor who will advise what to do. If people have severe symptoms, they should seek medical care immediately. Finally we may conclude that current clinical practice and evidence how to treat COVID-19 effectively in patients with COPD is limited. Lack of multicenter research studies on the topic \& lack of enough data is important limitation of this review, Knowledge of COVID-19 is rapidly accumulating; therefore, the discussion on how to best treat patients with COPD and COVID-19 should continue and we invite the respiratory community to share best practices online.

\section{References}

1. Mueller AL, McNamara MS, Sinclair DA (2020) Why does COVID-19 disproportionately affect older people? Aging (Albany NY) 12(10): 9959-9981.

2. Beth Sissons (2020) How does COVID-19 affect COPD? Medical News Today.

3. Rutkowski S (2021) Management Challenges in Chronic Obstructive Pulmonary Disease in the COVID-19 Pandemic: Telehealth and Virtual Reality. J Clin Med 10(6): 1261.

4. Sumedi, Philip K, Hafizurrachman M. The effect of Pursed Lips Breathing Exercises on the Oxygen Saturation Levels of Patients with Chronic Obstructive Pulmonary Disease in Persahabatan Hospital, Jakarta. The 4th International Virtual Conference on Nursing, KnE Life Sciences, pp: $35-64$.

5. Li W, Moore MJ, Vasilieva N, Sui J, Wong SK, et al. (2003) Angiotensin-converting enzyme 2 is a functional receptor for the SARS coronavirus. Nature 426(6965): 450-454.

6. Hoffmann $M$, Kleine-Weber $H$, Schroeder S, Krüger N, Herrler T, et al. (2020) SARS-CoV-2 cell entry depends on ACE2 and TMPRSS2 and is blocked by a clinically proven protease inhibitor. Cell 181(2): 271-280.

7. Walls AC, Park YJ, Tortorici MA, Wall A, McGuire AT, et al. (2020) Structure, Function, and Antigenicity of the SARS-CoV-2 Spike Glycoprotein. Cell 181(2): 281-292.

8. Zhou P, Yang XL, Wang XG, Hu B, Zhang L, et al. (2020) A pneumonia outbreak associated with a new coronavirus of probable bat origin. Nature 579: 270-273.

9. Leung JM, Yang CX, Tam A, Shaipanich T, Hackett TL, et al. (2020) ACE-2 Expression in the small airway epithelia of smokers and COPD patients: implications for COVID-19. Eur Respir J 55(5): 2000688.

10. Cai G, Bosse Y, Xiao F, Kheradmand F, Amos CI (2020) Tobacco smoking increases the lung gene expression of ACE2, the receptor of SARS-CoV-2. Am J Respir Crit Care Med 201(12): 1557-1559.

11. Li G, He X, Zhang L, Ran Q, Wang J, et al. (2020) Assessing ACE2 expression patterns in lung tissues in the pathogenesis of COVID-19. J Autoimmun 112: 102463.

12. Zhang H, Rostami MR, Leopold PL, Mezey JG, O'Beirne SL, et al. (2020) Expression of the SARS-CoV-2 ACE2 receptor in the human airway epithelium. Am J Respir Crit Care Med 202(2): 219-229. 


\section{Open Access Journal of Pulmonary \& Respiratory Sciences}

13. Leung JM, Yang CX, Sin DD (2020) COVID-19 and nicotine as a mediator of ACE-2. Eur Respir J 55(6): 2001261.

14. Russo P, Bonassi S, Giacconi R, Malavolta M, Tomino C, et al. (2020) COVID-19 and smoking: is nicotine the hidden link? Eur Respir J 55(6): 2001116.

15. Sungnak W, Huang N, Becavin C, Berg M, Queen R, et al. (2020) SARS-CoV-2 entry factors are highly expressed in nasal epithelial cells together with innate immune genes. Nat Med 26(5): 681-687.

16. Zou X, Chen K, Zou J, Han P, Hao J, et al. (2020) Single-cell RNA-seq data analysis on the receptor ACE2 expression reveals thepotential risk of different human organs vulnerable to 2019-nCoV infection. Front Med 14: 185192.

17. Rawson TM, Moore LSP, Zhu N, Ranganathan N, Skolimowska K, et al. (2020) Bacterial and fungal coinfection in individuals with coronavirus: a rapid review to support COVID-19 antimicrobialprescribing. Clin Infect Dis ciaa530.

18. Zhou F, Yu T, Du R, Fan G, Liu Y, et al. (2020) Clinical course and risk factors for mortality of adult inpatients with COVID-19 in Wuhan, China: a retrospective cohort study. Lancet 395(10229): 1054-1062.

19. British Thoracic Society (2020) COPD and COVID-19 for healthcare professionals.

20. van Geffen WH, Douma WR, Slebos DJ, Kerstjens HAM (2016) Bronchodilators delivered by nebuliser versus pMDI with spacer or DPI for exacerbations of COPD. Cochrane Database Syst Rev 29(8): CD011826.
21. Ferioli M, Cisternino C, Leo V, Pisani L, Palange P, et al. (2020) Protecting healthcare workers from SARS-CoV-2 infection: practical indications. Eur Respir Rev 29: 200068.

22. Wu C, Chen X, Cai Y, Xia J, Zhou X, et al. (2020) Risk factors associated with acute respiratory distress syndrome and death in patients with coronavirus disease 2019 pneumonia in Wuhan, China. JAMA Intern Med 180(7): 934-943.

23. Alhazzani W, Møller MH, Arabi YM, Loeb M, Gong MN, et al. (2020) Surviving sepsis campaign: guidelines on the management of critically ill adults with coronavirus disease 2019(COVID-19). Intensive Care Med 46(5): 854-887.

24. Bräunlich J, Köhler M, Wirtz H (2016) Nasal highflow improves ventilation in patients with COPD. Int J Chron Obstruct Pulmon Dis 11: 1077-1085.

25. Osadnik CR , Tee VS , Carson-Chahhoud KV , Picot J, Wedzicha JA, et al (2017) Non-invasive ventilation for The management of acute hypercapnic respiratory failure due to exacerbation of chronic obstructive pulmonary disease. Cochrane Database Syst Rev 7(7): CD004104.

26. de Miguel-Diez J, Jiménez-García R, HernándezBarrera V, Puente-Maestu L, Girón-Matute WI, et al. (2019) Trends in the use and outcomes of mechanical ventilation among patients hospitalized with acute exacerbations of COPD in Spain, 2001 to 2015. J Clin Med 8(10): 1621. 